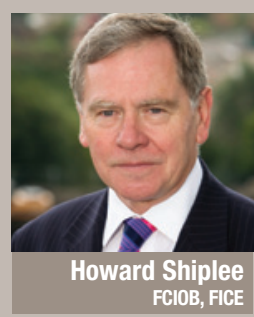

is director of construction at ODA

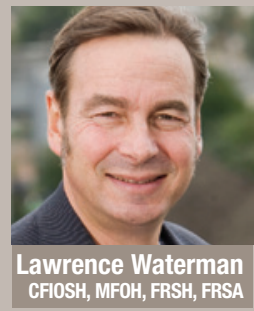

is head of health and safety at ODA

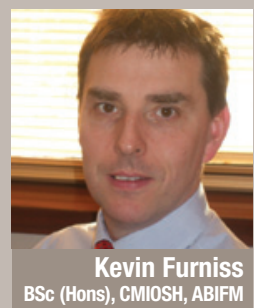

is head of health and safety at CLM

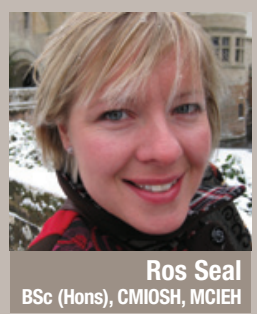

is health and safety advisor at ODA

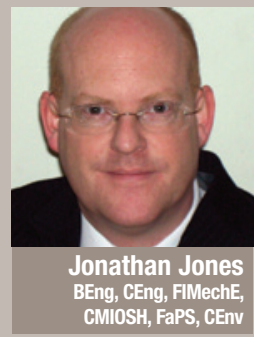

is CDM integrator at CLM

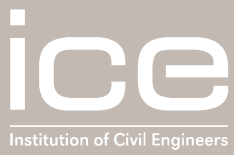

\title{
Delivering London 2012: health and safety
}

\author{
This paper describes the challenge of managing health and safety \\ during construction of the London 2012 Olympic and Paralympic \\ Games. The workforce on the Olympic Park site in east London \\ peaked at I2 000 and a total of 30000 people will have worked \\ on the project through its lifetime. Through careful planning, \\ implementation of strategies with a proven track record and clear \\ leadership, the Olympic Delivery Authority managed to achieve an \\ accident frequency rate comparable to the average for all British \\ employment, significantly better than the construction sector. The \\ project's health programme also provided a degree of care and \\ campaigning not previously experienced in construction.
}

The management of health and safety on the London 2012 Olympic and Paralympic Games construction programme encompasses the Olympic Park, the largest regeneration project in Europe, the Athletes' Village, Europe's largest new housing project, and several other sites. With a peak workforce of over 12000 , and a churn resulting in approximately 30000 people working on the programme during its life, the background of an industry recognised for a poor health and safety record and a demanding construction timetable, achieving excellent health and safety performance presented a challenge.

The UK Health and Safety Executive (HSE) statistical digests (HSE, 2010) in accordance with the Reporting of Injuries, Diseases and Dangerous Occurrences Regulations 1995 (Riddor) (HSE, 2008) show that the UK construction industry contributes disproportionately to reported workplace accidents and resulting injuries. If the UK Olympic Delivery Authority's (ODA) programme of construction mir- rored the sector average, there would be approximately 1000 accidents reportable under Riddor (HSE, 2010) on the project, a considerable number of which would lead to major injuries and permanent disabilities for the workers involved.

Furthermore, as has been noted in Constructing Better Health final evaluation report (Tyers et al., 2007), the 'health' part of health and safety, especially in construction, has not historically been addressed adequately and proportionately. Together with the predominately male and ageing workforce, this has left a considerable gap in health management.

The International Olympic Committee awarded the 30th Olympiad and Paralympic Games to London in July 2005. It crystallised the promise in London's bid to create through major construction works an Olympic Park, sporting venues, associated infrastructure, an Athletes' Village and a long-term legacy for east London. It was estimated that the activities required would take approximately 60 million worker hours to demolish over 200 build- 
ings, construct roads, bridges, underpasses and footpaths, complete landscaping, dredge and widen rivers and build major sporting venues including the Olympic Stadium, Aquatics Centre and Velodrome as well as 3000 housing units, a school and a polyclinic.

London was in the middle of a construction boom, so recruiting and retaining enough workers was an associated challenge in building, the equivalent of two Heathrow Terminal $5 \mathrm{~s}$ in half the time.

\section{Health and safety aspirations}

From its formation, it was clear to ODA and the UK government's Department for Culture, Media and Sport that the process by which venues and infrastructure for London 2012 were to be constructed should reflect the Olympic and Paralympic ideals and ensure the health and welfare of the construction workforce. This is reflected in ODA's health, safety and environment policy statement.

'The protection of the health and safety of everyone involved in our work or affected by it ... is important to us ... Our vision is to go beyond eliminating preventable illnesses, injuries, business losses and environmental harm ... it extends to enhancing the well-being of all involved in our project work (ODA, 2010).

If the main and predominant driver for high health and safety performance was the protection of the workforce during the works themselves, another aspiration which chimed with the approach of ODA as a whole was to create a positive, lasting legacy. This was expressed in many ways, from the early launch by ministers and the ODA chief executive officer David Higgins of the 2012 construction commitments (Strategic Forum 2012 Task Group, 2006), to the following statement by the then HSE chief inspector of construction Stephen Williams in an address to the Olympic Board steering group.

'We (the HSE) see London 2012 as a way of leveraging improvements across UK construction. Delivery is crucial, this is a flagship project that can stimulate a step-change for the whole industry.
The key components are a clear policy statement, a transparent organisation with mechanisms to deliver excellence, a process to change cultures so that health and safety really matters and through this to become a beacon of excellence.'

This paper outlines the ODA health and safety programme from specification and procurement through to audit, review and the public reporting on performance. Examples are cited as to how the programme had a practical impact, although the emphasis throughout is to provide an overall summary.

\section{Programme overview}

The complexity of the works and the large numbers of workers that would be involved represented a significant challenge. In addition to the sites in Weymouth and Portland (sailing), Broxbourne (canoeing), Eton Dorney (rowing and flat-water kayaking) and Royal Artillery Barracks (shooting), ODA was responsible for transforming an old multi-use site with significant contamination and waste dumps, criss-crossed by railway lines, waterways and roads into a coherent and attractive park containing many of the key venues for the London 2012 Games and representing a legacy for east London.

During the transformation, it would prove necessary to demolish over 200 buildings, move nearly $1.8 \mathrm{Mt}$ of soil, and pass over half of it through soil washing and other mechanisms to remove enough contamination in order to reuse the material. Although the peak workforce at Heathrow Terminal 5 was less than 10000 workers, over 70000 were inducted in the course of the construction - at peak over 30000 workers would pass through the Olympic Park entry plazas involved in different packages of work. With time constraints and huge public scrutiny, this was a programme presenting great challenges in establishing a health and safety culture, a way of working across the programme that could defy the statistical averages and enable the supply chain to strive for the aspiration of ODA to reduce reportable accidents to less than one for every million hours worked.

As a developer, and a procurement body, ODA recognised that the key to per- formance is leadership. From the outset ODA established a leadership and governance structure which grew and developed, from the autumn of 2005 when ODA was an interim body through to its organisational maturity. This placed health and safety considerations at the heart of management.

Professional health and safety advice was available through direct lines of communication to the ODA executive directors, in particular the director of construction and chief executive. Thus the arguments which have been used over the years to the effect that the head controls the body, that the leadership of an organisation determines what its priorities are and what it will achieve within the limits of external constraints, were accepted and influenced how ODA approached health and safety.

The reasons for the focus on health and safety were threefold.

ODA accepted fully that it had a moral obligation to seek to minimise harm to its workforce. The desire to prevent fatalities and ensure that everyone went home safely every day was very strong.

Legally, ODA as client had duties under the Health and Safety at Work etc Act 1974 (1974) and subsidiary legislation particularly the Construction (Design and Management) Regulations (HMG, 1994).

- Good management is responsible for managing risk - and the risks to the programme, including the risk to the reputation of ODA and its sponsoring department, certainly encompassed the impact that serious accidents and/or work-related ill health could have.

It was deemed unacceptable to work 'business as usual' and suffer a thousand reportable personal injury accidents. Similarly, it was deemed unacceptable that workers on site would have their health ignored. When work started the credit crunch was still way in the distance, the London construction sector was booming so that recruitment and retention of skilled workers by ODA suppliers was a potential threat to the whole programme. The Terminal 5 project had set its benchmark as one in a million, that is, a Riddorreportable accident for every 1 million 
hours worked, and this remains a stretching, demanding aspiration.

The health and safety programme is governed by the ODA board and through its executive and delivery partner CLM (a joint venture between $\mathrm{CH} 2 \mathrm{M}$ Hill, Laing O'Rourke and Mace) through to the supply chain (Figure 1).

\section{Strategy for excellence}

The main objective of the whole approach to managing the construction programme was to unlock the abilities of suppliers to deliver excellence. So, from the outset, this was not a strategy based on micro-managing the works, operating a centralised client-led command and control system. Instead it was recognised that the major companies that bid and were appointed as tier 1 contractors (principal contractors) had done so because they wished for the high profile intrinsic to participating in the London 2012 works.

Willingly positioning themselves in this way created a reputational risk as well as a marketing opportunity, and to mitigate that risk the companies had to appoint some of their best people, respond rapidly to any issues arising and achieve excellence to seize that opportunity. This established a supply chain that at the top end, tier 1 , was truly committed to an excellent health and safety performance. The main objective of ODA was to realise that commitment in practice.

Health and safety as a priority theme was woven into everything ODA did. In the sequence of interventions, the work of delivery partner CLM was crucial, as the organisation that converted ODA requirements into facts on the ground. In summary, the programme operated as follows.

The base case for each project, the design brief and specifications, the methods of procurement and the wording of contracts and works instructions, all reflected ODA's requirements. As a new body with no history, the adoption of a health and safety standard that was developed through wide consultation with trades unions, industry bodies, HSE and professional institutions was a very important early achievement. For a client body to consult to confirm that what it was doing rep- resented evidence-based best current practice was a major innovation that resulted in the incoming suppliers fully embracing the standards required.

- A peer group was established early in 2006, comprising leaders across the industry who freely gave their time and expertise to the drafting of a standard that represented the best that the industry had done hitherto to achieve high performance. These standards were then developed so that a set of site common standards addressed generic issues, such as the protection of buried services, the role and competence of supervisors and much more. This effective consultation with peers and experts to establish an agreed standard was unprecedented, reflecting the transparency of ODA.

- Design management included the unique appointment of a Construction (Design and Management) (CDM) Regulations integrator, to assist in managing the many CDM coordinators appointed across the projects in accordance with ODA's regulatory obligations as client, under 1994 and then soon to be adopted $2007 \mathrm{CDM}$ Regulations (HMG, 1994, 2007).

- Within each project, the CDM coordinator was an appointment made initially through the design team and as soon as possible through the integrated team operating under the tier 1 . This helped to embed the whole approach to 'safe and healthy by design' within the team as originally envisaged both by the UK government's construction task force and by European legislators.

- On site there were two main thrusts to the strategy - a leadership programme and assurance at project level through routine and regular scrutiny by a team of health and safety practitioners that the standards set out were being complied with.

There were five key elements to the health and safety programme, as follows.

Safety - clear policies, risk assessments, method statements, common standards, visual standards, daily activity briefings.

Health - pre-employment medical checks, prevention programme, assessment and control, health surveillance, training, emergency response.

- Well-being - advice, well man/woman clinics, good food strategy, campaigns, sexual health clinics, partnerships.

- Competence - induction, training, supervisor academy, briefings, apprenticeships, checks and records.

- Culture - leadership, action plans, near-miss reporting, communications, reward and recognition, climate tool.

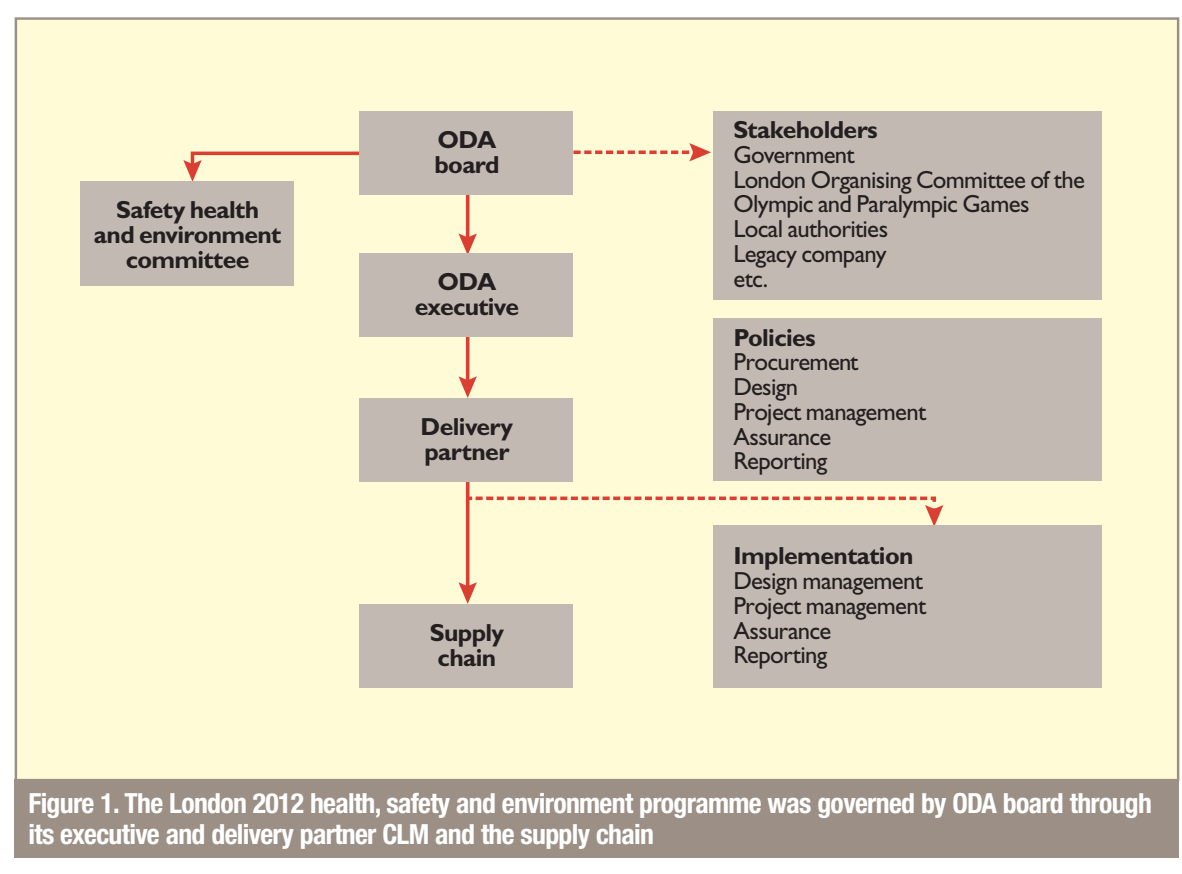


The components of ODA's health and safety system were as follows

business case, design brief, construction specification, health, safety and environment plan

- procurement, pre-qualification questionnaire, invitation to tender, evaluation process

- contract, works instructions

- design and CDM coordinator integration

- pre-commencement planning, including reviews of health, safety and environment plan and detailed method statements (where applicable)

works delivery, project and programme management

health (Park Health and Village Health)

- on-line reporting: incidents, accidents, monthly scorecard

worker engagement

assurance programme (delivery partners)

- site communications

- leadership programme

- reporting: performance including accident frequency rate, achievements and issues, forward plans.

\section{Leadership for high performance}

Since the 1980s there has been a growing body of evidence that effective lead- ership and the establishment of a good, positive health and safety culture are fundamental to achieving high health and safety performance (CBI, 1991) Creating the right leadership was an early priority, and there were three strands to leadership: within ODA, across the programme and at project level.

ODA established a leadership board, chaired by the chief executive officer and attended by the ODA chairman, the safety health and environment committee, executive directors, including the director of construction and members of the senior team for the delivery partner. The board met periodically to review the strategy and approve the initiatives being taken. Having made arrangements for this high level support, which was also evidenced by the senior staff participating in awards events both on site and centrally (Figure 2), site tours and other engagements with each project, the focus moved to engaging the senior staff in the project teams.

A safety health and environmental leadership team was formed with over 20 tier 1 members, each representing at the highest level the projects on the ground together with senior staff from the delivery partner and just three ODA representatives - director of construction and heads of health and safety and of environment. After an initial period of self-management, an independent experienced construction professional was appointed chairman.

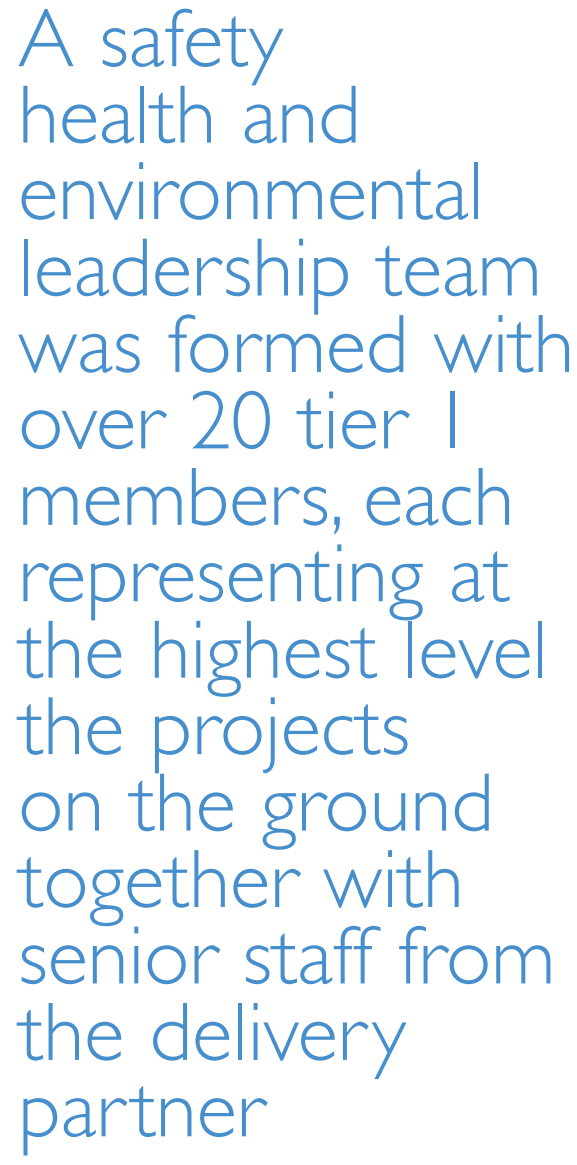

A safety

health and

environmental

leadership team

was formed with

over 20 tier

members, each

representing at

the highest level

the projects

on the ground

together with

senior staff from

the delivery

partner

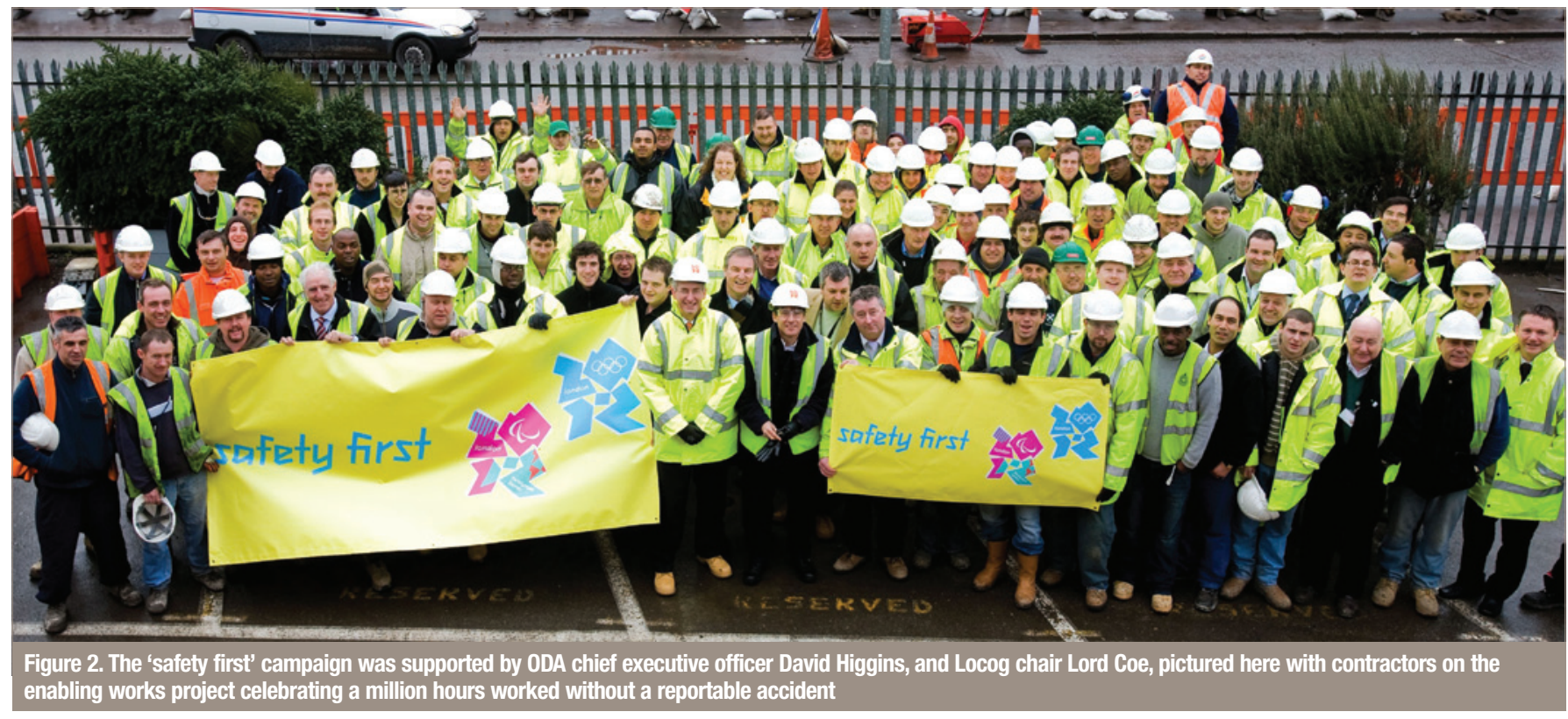




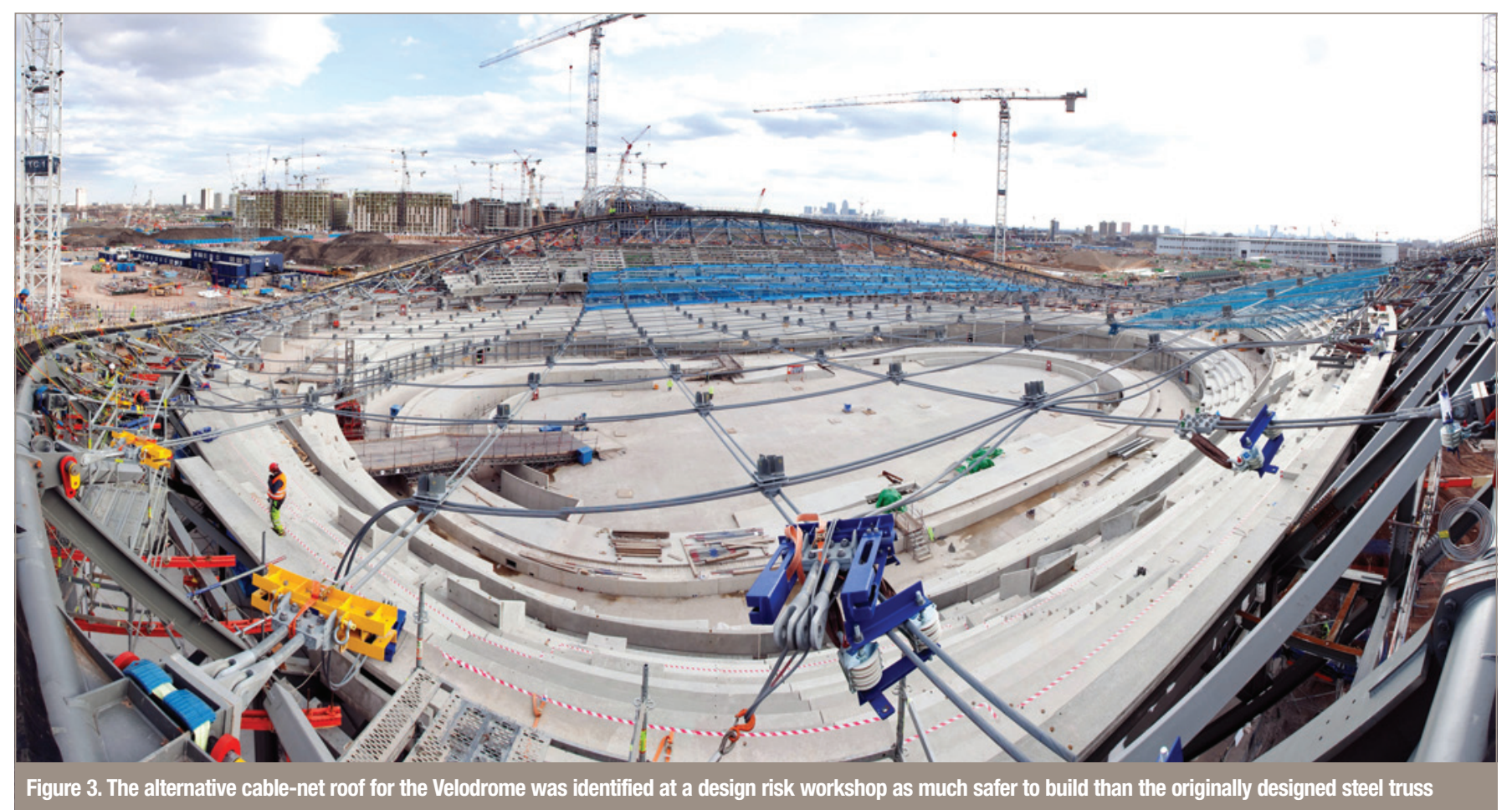

The leadership team was responsible for a wide range of very specific initiatives and innovations including

banning semi-automatic quick hitches, and eliminating them within weeks

- establishing a mandatory supervisor course on leadership and behaviour

- campaigns on buried services timed for them going live

agreeing visual standards and then using them to achieve good housekeeping

achieving over $60 \%$ worker participation in the use of the climate tool every year

- ensuring that on every project there was a behavioural safety programme and really effective worker consultation.

The crucial link to each project was created through the formation of individual project leadership teams.

\section{Designing for safety and health}

It has been claimed that some $6 \%$ of all fatal accidents arising from falls from height are related to permanent works design (Gambatese et al., 2008) thus stimulating efforts to reduce risks through design review and development. To this end, as well as developing policies covering the key issues such as principal contractor allocation across a large, complex site with many project coordinators, ODA appointed a CDM integrator responsible for managing and coordinating the CDM coordinators, to ensure maximum value from their interventions and also a degree of consistency across so many projects - a single structure for health and safety files, for example. A detailed discussion of the ODA approach to CDM compliance, specifically the role of CDM coordinator, is provided by Scopes (2009)

An illustrative case of the value of seeking better design is the Velodrome venue. The architectural form of the Velodrome was driven by the sightlines of the spectators, themselves directly related to the geometry of the track. The concept was to take that geometry, which resembles a wrapped ribbon, and project the same visual qualities into the structure of the building and roof. The Velodrome design team affectionately described the roof as looking like a crisp.

The initial concept design of the Velodrome roof proposed at Royal Institute of British Architects (Riba) design stage $\mathrm{C}$ consisted of a steel truss roof design which would have been erected from a crash deck. Although constructable, this would have been restrictive for the site and would have led to a significant amount of construction work carried out at height with temporary support structures installed. All of these issues would in turn have created significant health and safety risks for the construction workers, and introduced long-term maintenance risks for the venue operator.

The design risk register produced by the designers in consultation with the tier 1 contractors identified the potential risks. It was quickly identified by the CDM coordinator and design team that a design risk workshop on the Velodrome roof was needed to explore alternatives to the proposed steel truss roof design. The roof risk workshop identified the advantages and disadvantages of alternative roof designs and their real impact on reduced health and safety risks.

Following the design risk workshop, it was concluded that a safer and more cost effective roofing solution was a cable-net roof design, proposed and accepted at Riba design stage D. The cable-net design solution raised interest from within HSE, which was keen to understand the innovative roof proposal for the Velodrome. The cable net was assembled at ground level, 

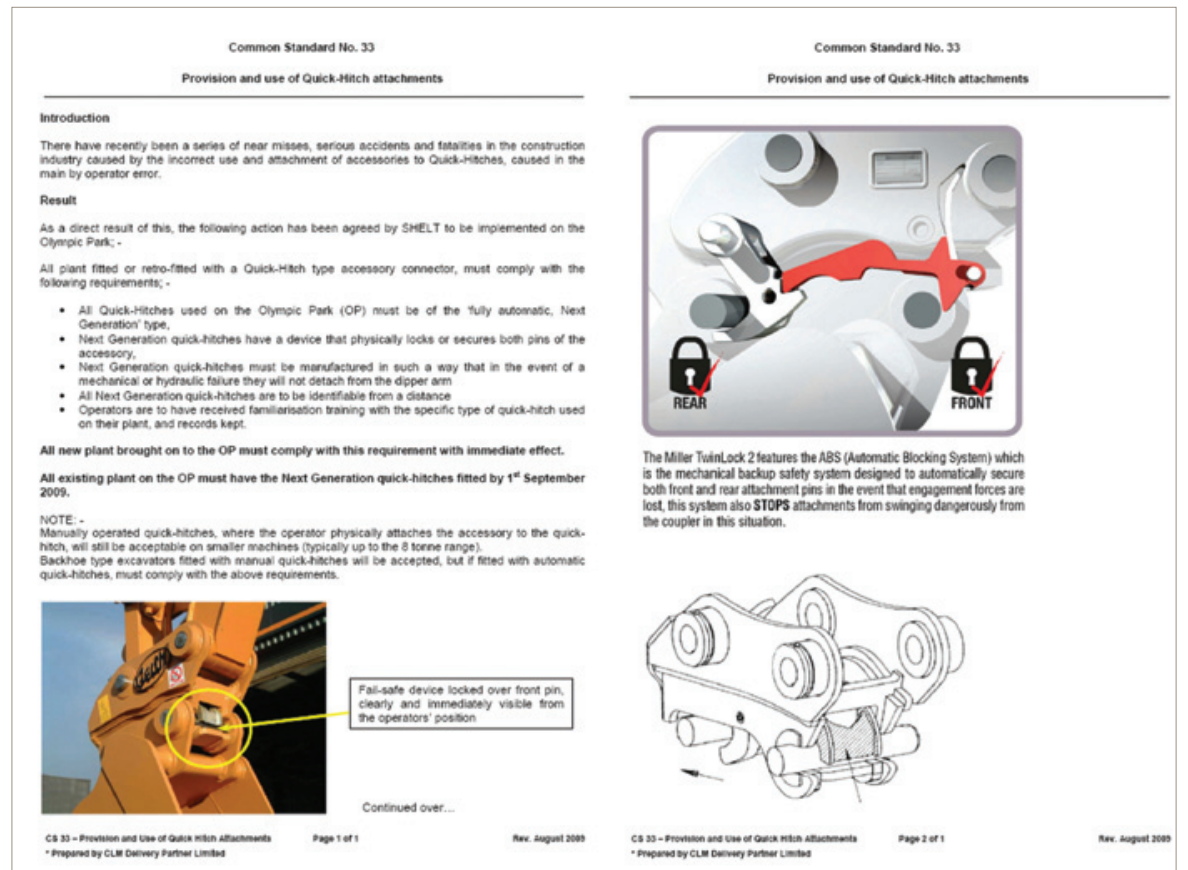

Figure 4. Example of a London 2012 common standard issued to all tier 1 contractors - this one was on the mandatory use of fully-automatic quick hitches on excavators

fixed to node points and hydraulically jacked into its final position (Figure 3).

The node points are movable joints which allow the roof to flex and move in use. Timber casket inserts were fitted into the $3.6 \mathrm{~m}$ square mesh grid, with a metal standing-seam roof cladding providing the finish.

Temporary handrailing was fixed to the leading edge of the roof during the construction works. The cable-net roof design solution reduced the need for construction workers to work at height, since the majority of the assembly work could be carried out at ground level.

The innovative roof design clearly demonstrated the ability of the design team and the CDM coordinator to challenge earlier design decisions and reduce health and safety risks. It was a fundamental requirement on the Olympic Park that any design solution that reduced health and safety risks to construction workers and the end user of the structure was captured and shared with other London 2012 venue design teams through design best practices forums and CDM coordination meetings organised by the CDM integrator. The Velodrome roof was just one of many such design innovations shared across the programme.

\section{Implementation on site}

If ODA's benchmark expectations on achieving top-class performance on health and safety were to be delivered, successful implementation at project level would be critical. This meant that each project's leadership, planning and workplace organisation, systems and procedures, and probably most importantly, behaviour and culture programmes would need to be robust and fully effective from very early on.

On the Aquatics Centre project, for example, a significant amount of planning and organising took place in a relatively short space of time. What initially looked like a simple large work site soon became a challenging work area with a number of concurrent activities taking place. Consideration was given to safety of the activity and adjacent work activities, the needs of the programme and logistical requirements. All activities on the project were subject to thorough planning and review processes. The principal activities involved movement of heavy plant, significant lifting operations and placing large volumes of reinforcement and concrete in the early stages of construction.

The interface between workers and

\section{Olympic Park common standards were developed to drive a degree of consistency in health and safety management across all the projects.}

machinery was one of the significant considerations in all activities on site. A further complication was the high water table and the need to work within a sheet pile cut-off wall with a de-watering system in place. One of the key mechanisms for recording and communicating the changing workplace was a 'weekly overview' process that indentified key areas of interface and associated risks.

A number of Olympic Park common standards were developed to drive a degree of consistency in health and safety management across all the projects. These standards, defining high level expectations in a wide range of technical areas, were collaboratively developed with tier 1 representatives to set minimum expectations that would 'raise the bar' in terms of health and safety performance. An example was the standard on excavator quick hitches (Figure 4), which outlined the requirement that all machines be fitted with secondgeneration, fully-automatic quick hitches as a minimum and banned the use of semiautomatic quick hitches on Olympic Park and Athletes' Village projects.

Implementing standards was further enhanced by a set of supporting documents that illustrated workplace conditions and personal behaviours to clearly 
communicate 'what good looks like'. These visual standards were used by the Aquatics Centre team in a number of ways: communicating health and safety expectations to teams; checking conditions on site inspections; and as leadership tools in management-by-eyesight tours. The nature of the documents also meant that workers for whom English was a second language were still able to understand site requirements and participate in safetyrelated activities. An example of a visual standard is shown in Figure 5.

The effective implementation of ODA's contractual standard on health, safety and environment and all other associated common standards was monitored by a multi-layered assurance programme based on validation and verification of tier 1 self assessments. The Aquatics Centre team undertook monthly self assessments covering design, $\mathrm{CDM}$ coordination and project construction against a set of health and safety performance criteria, and submitted these on a web-enabled database in the form of evidence-based scorecards. The project scorecards were sampled by the delivery partner health and safety assurance team at varying frequencies dependant upon risk and performance - but at intervals no less than twice in a 12-month period per project.

Behaviour and cultural aspects of health and safety on the Aquatics Centre was delivered through its 'zero harm - making safety personal' programme. This was founded on its management and supervisory teams demonstrating a set of consistent and persistent leadership behaviours that seek to challenge and engage with the workforce in a positive way. They held supply chain conferences for tier 2 and 3 suppliers planning to work on the project, explaining the zero-harm vision and set- ting expectations in terms of health and safety on site.

Making safety personal was part of the overall project management system and the programme is behavioural based. The initial roll out was carried out in October 2008 when 75 people attended a 1-day session designed to provide attendees with the knowledge and skills needed to have positive interactions with people on site and achieve improvements in standards. The programme was based on a ' $3 \mathrm{Cs}$ ' approach: concern for the individual; conversation; and coaching to achieve compliance. Measurement of the effectiveness of the programme was via ODA's working at London 2012 survey.

Having a competent workforce is a major contributor to good health and safety performance. It was a fundamental requirement that all workers on the Olympic Park must hold a recognised com-

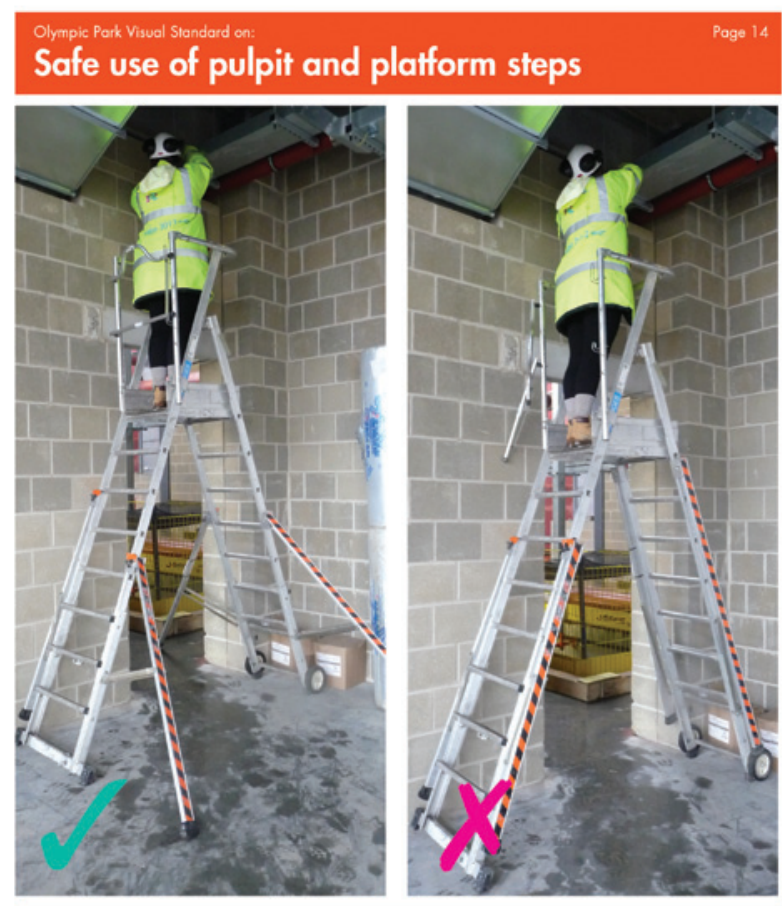

Poge 14

\section{Key points:}

- A risk assessment and method statement should identify when pulpit steps should be used

- Only those who hove received appropriale training should undertake ony work ot height - Access equipment for any work at height must be erected on a firm, level bose

- Individually numbered, inspected and maintained

- Outriggers must be used to increase stability and gates closed

\begin{tabular}{|l|l|l|l|l|l|}
\hline Slandard no. & VS14.0 & Dale issued: & October 2010 & lssue: & P1 \\
\hline
\end{tabular}

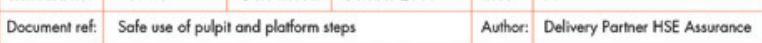

Figure 5. Example of a visual standard on safe (and unsafe) use of pulpit steps

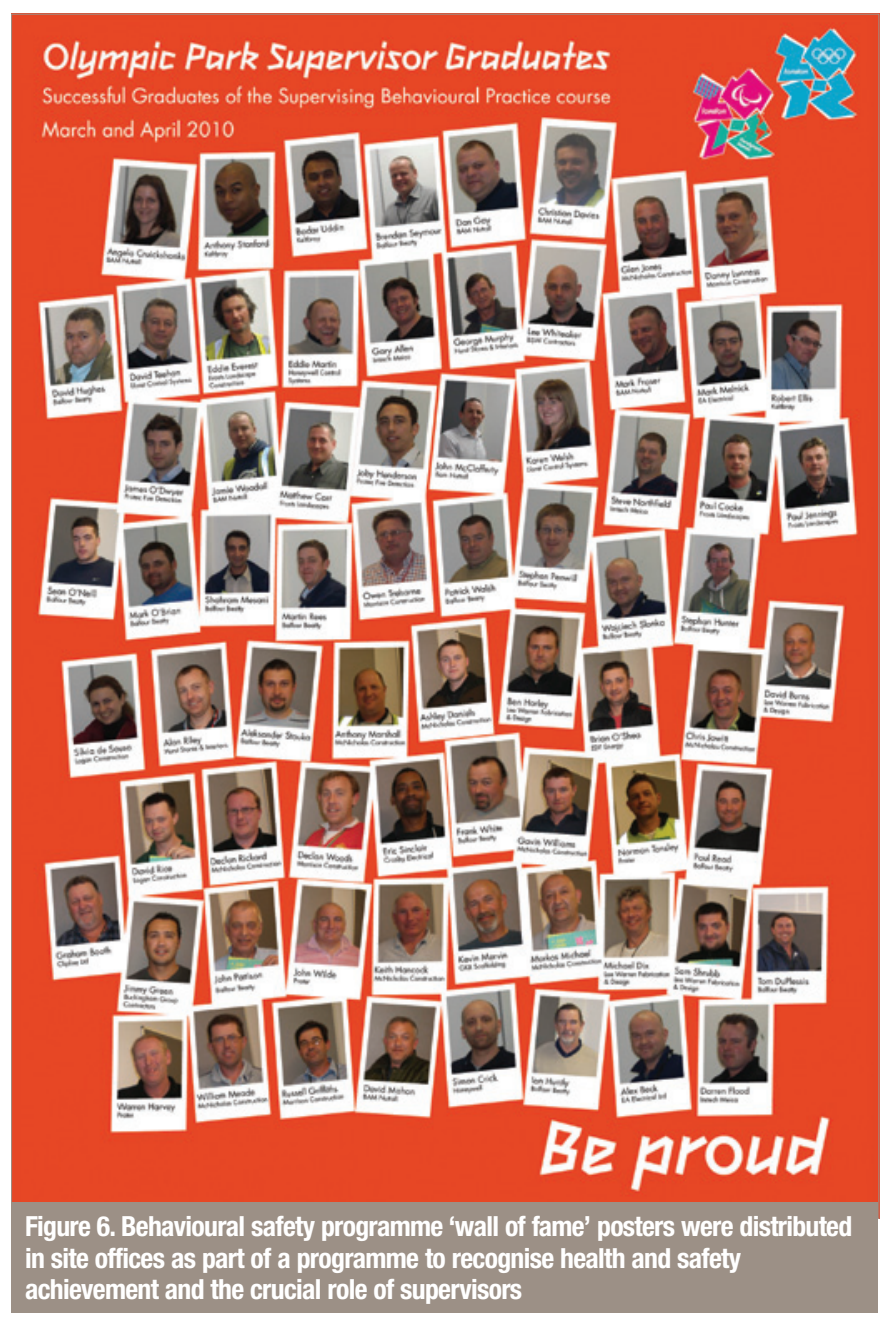


petence card such as construction skills certification scheme or construction plant competence scheme. The Aquatics Centre team had processes in place to ensure all workers on its project met with the basic minimum standards, and continually worked with its supply chain to develop the competence of every person working on the project. A nominated training coordinator recorded baseline data of all employees and supervisors. Records of existing training requirements were then compared with the minimum competency requirements and plans developed to address any gaps in existing training.

A comprehensive communications programme was developed that utilised a number of different mediums to ensure the maximum exposure. Park-wide communications were supplemented by the Aquatics Centre team to ensure that the understanding of key messages meant something locally to its work teams.

\section{Leadership within a project}

The team constructing the Olympic Stadium adopted and developed what has become the Olympic Park approach to creating real, visible leadership around health and safety through a variety of means. The project leadership team met monthly, involving senior staff from the tier 1 and a representative from each of the tier 2 and 3 package subcontractors. The team sought to take a high profile lead in promoting high standards of health and safety, and encouraged everyone to get involved and stay engaged. The fol- lowing are examples of project leadership team initiatives.

Near-miss reporting - a crucial aspect of understanding what is going on and enabling action to be taken before real accidents occur. The best reports, a little like operating a suggestions box, get recognised and rewarded. They all trigger a 'you said, we did' report back to all workers on site through notice boards.

- Behavioural safety programme launched following three incidents, and operated through workshops and training for all managers, supervisors and workers on site (Figure 6). This undoubtedly contributed to the following long period (four months) without a reportable incident.

Similar descriptions hold true for other venues such as the Media Centre, and for infrastructure projects and work on the Athletes' Village.

\section{Occupational health}

The health and well-being of the site workforce was also central to the overall health and safety programme (Figure 7). There is good evidence that far more workers are harmed by exposure to hazards to their health - dusts, fumes, dermatitic agents, vibration, noise and many other factors - than are injured in accidents (Zimmer, 2007). The services of professional teams based on the Olympic Park and within the Athletes' Village ensured there was attention to these risks.
The health initiatives covered a variety of matters

pre-employment health checks, including medicals for safety critical workers

advice to identify safer substitute materials and methods

- assistance with controls on exposures to chemical, physical and ergonomic hazards

- health surveillance

drop-in treatment centres

campaigns on well-being (e.g. heart, obesity, diet, diabetes, sexual health)

- emergency call-out with ambulance services operated by paramedics.

The services were well respected, demonstrated by survey results and the willingness of London Ambulance Service to sign a memorandum which uniquely identifies a private health provider as 'first responder' in the event of a health emergency. To capture the lessons from this comprehensive programme, HSE and ODA jointly funded an independent evaluation by the Institute of Employment Studies.

\section{Reward and recognition}

One of the overriding impressions that health and safety programmes can convey is that of a focus on what is wrong, what can cause harm. For example, many workers will 'see' health and safety when inspections are conducted, and all that is commented upon, noted and followed up are non-compliances with site rules.
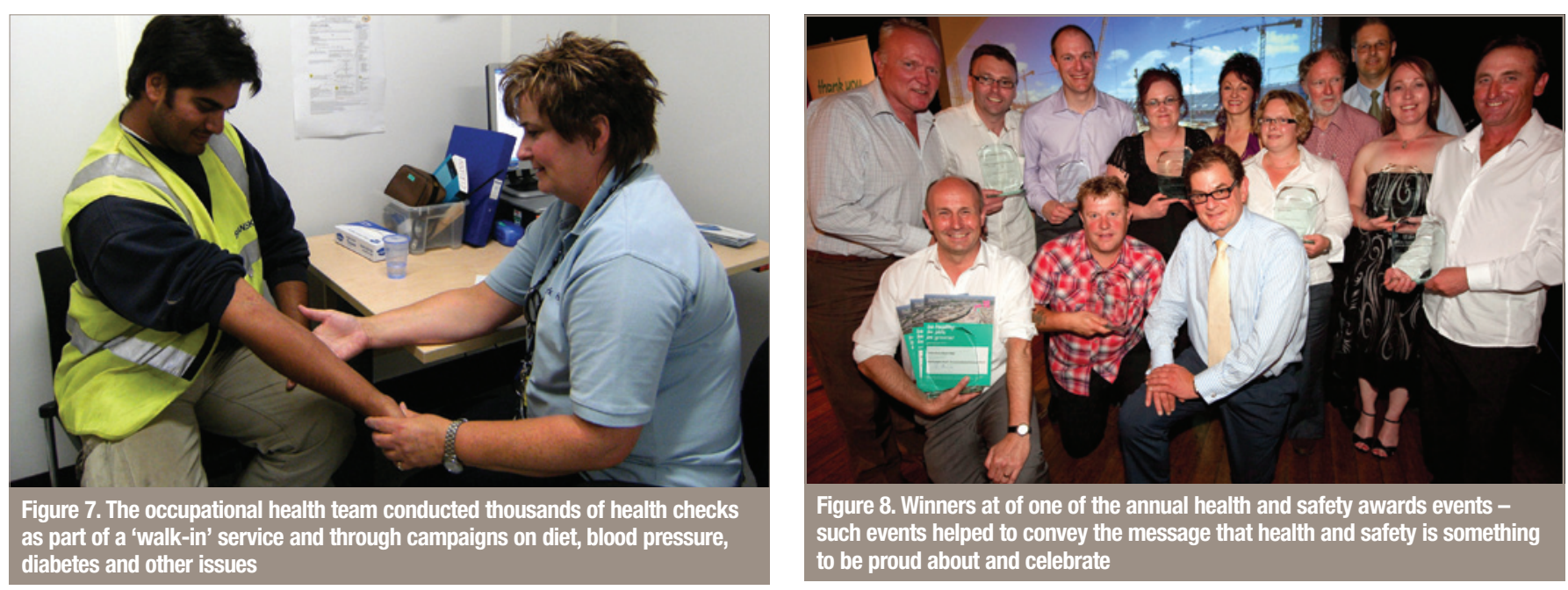
This wholly negative approach is not consistent with efforts to engage, involve and enthuse people to create exemplar projects and exemplar sites, it is inimical to attempts to 'raise the bar' in health and safety across London 2012 and indeed across the industry.

From the early stages of the works it was agreed that ODA would celebrate health and safety performance, would note and mark every possible achievement, would create an impression of winning, of protecting people by doing a great job. This is best illustrated at the various levels through the programme of works.

\section{Project level}

Many individual projects adopted an immediate reward for excellence strategy, including providing free breakfasts to everyone for every week without a reportable accident, or a breakfast voucher to everyone seen on a manager or safety representative's tour who was working safely, wearing the correct personal protective equipment, and so on. On some projects this included tangible rewards - such as radios and televisionsfor good near-miss reports that helped improve safety management.

In all cases, the emphasis was on a public display of thanks, that is, in front of the whole workforce people were thanked for exhibiting the behaviours that ODA wished to encourage. This was a refreshing change from public humiliation (in many workplaces workers are shouted at and worse for the opposite behaviours), and accorded with decades of research into what inculcates an effective and sustainable safety culture.

\section{Site level}

The sharing of health and safety information across the programme at monthly health, safety and environment forum meetings attended by project managers and others from every project created a public opportunity to congratulate teams for particular success - for example for good investigations of high potential near-misses so that everyone could learn the lessons.

The delivery partner initiated three awards with different criteria, each presented every quarter, so that each month one team or another could be extolled in front of their peers for contributing to safer and healthier sites.

\section{Programme level}

At the highest level, an annual awards event was held at which excellent performance by individuals and teams was acknowledged (Figure 8). The awards themselves were wholly independently assessed by an external team assembled from the construction and health and safety professions, and were hosted by the chief executive, chairman and directors of ODA.

From the apprentice of the year and worker of the year awards to the successful project teams, the process itself encouraged everyone to think about what they were doing positively to achieve excellence there were over 150 nominations for some awards. The event itself, attended by workers, supervisors, managers and directors and its follow-up in on-site material such as a supplement to the site newspaper Park Life, ensured that everyone got the message: health and safety is something to be proud about and to celebrate.

\section{Lessons learned - conclusion}

Through careful planning, the implementation of strategies that have a proven track record and, above all, clear leadership, even the most complex construction programme can be safely managed. It is important that this is done systematically, which is why ODA is the first delivery authority for a games to have its health and safety management system certified against the internationally recognised standard OHSAS 18001.

In the first 5 years on site, with more than 50 million hours worked, the accident experience was comparable to the average for all British employment rather than just for construction, and the health programme provides a degree of care and campaigning not previously experienced in the industry.

The necessity for continued improvement is emphasised by the fact that the challenging benchmark of an accident frequency rate better than $0 \cdot 1$ was not reached. However, the good performance has contributed to the projects hitting and beating their targets for delivery timetable and cost control. Healthy and safe projects are also efficient, and the time spent on health and safety represents a sound investment rather than an on-cost.
Acknowledgements and dedication

The performance across the programme was achieved through the commitment and hard work of too many people to name - but the paper is dedicated to the members of the safety health and environment leadership team, to the Park Health and Village Health staff and the team of health and safety practitioners within projects and contractors and the delivery partner, who continued to work tirelessly for excellence.

\section{References}

CBI (Confederation of British Industry)(199I) Developing a safety culture. CBI, London.

Gambatese J A, Behm M and Rajendran S (2008) Design's role in construction accident causality and prevention: Perspectives from an expert panel. Safety Science, 46(4): 675-69I.

Health and Safety at Work Etc. Act, 1974 (1974) Elizabeth II. Chapter 37. Her Majesty's Stationary Office, London.

HMG (Her Majesty's Government)(1994) The Construction (Design and Management) Regulations 1994. The Stationary Office, London, Statutory Instrument 1994 No. 3140.

HMG (Her Majesty's Government)(2007) The Construction (Design and Management) Regulations 2007. The Stationary Office, London, Statutory Instrument 2007 No. 320.

HSE (Health and Safety Executive)(2008) A guide to the reporting of Injuries, Diseases and Dangerous Occurrences Regulations (RIDDOR) 1995. HSE Books, London, UK.

HSE (2010) Health and Safety Statistics 2008/09. HSE Books, London, UK.

ODA (Olympic Delivery Authority) (2010) Design and Construction: Health, Safety and Environment Standard, 4th edn. ODA, London, UK.

Scopes J P (2009) London 2012: A new approach to CDM coordination. Proceedings of the Institution of Civil Engineers - Civil Engineering, 162(2): 76-86.

Strategic Forum 2012 Task Group (2006) 2012 Construction Commitments. See http://www. strategicforum.org.uk/2012CC.shtml (accessed 20/02/20II).

Tyers C, Sinclair A, Lucy D, Cowling M and Gordon-Dseagu V (2007) Constructing Better Health Final Evaluation. HMSO, Norwich, UK. HSE Research Report - RR565.

Zimmer S (2007) Global cycle on challenges posed by occupational diseases: Results 2005-2007. International Social Security Association, Geneva, Switzerland. 